\title{
Performance Improvement of a Bidirectional DC-DC Converter for Battery Chargers using an LCLC Filter
}

\author{
Sang-Ho Moon*, Sung-Tak Jou* and Kyo-Beum Lee ${ }^{\dagger}$
}

\begin{abstract}
In this paper, a battery charger is introduced for an interleaved DC-DC converter with an LCLC filter. To improve the overall performance of the DC-DC converter for battery charger, a method is proposed. First, the structure of the system is presented. Second, an LC filter is compared to an LCLC filter in terms of the response characteristics and size. Third, the small-signal model of a bidirectional DC-DC converter using a state-space averaging method and the required transfer functions are introduced. Next, the frequency characteristics of the converter are discussed. Finally, the simulation and experimental results are analyzed to verify the proposed state space of the bidirectional converter.
\end{abstract}

Keywords: Bidirectional, DC-DC converter, Battery charger, LCLC filter, State-space averaging

\section{Introduction}

Recently, industry development has led to a steady increase in pollution that has become a serious global problem. For this reason, many research activities in the energy storage system (ESS) have been conducted [1-3]. The charge-discharge system, one of the ESSs, must ensure stability because it is connected to the battery $[4,5]$.

In hybrid electric vehicles and rail-guided shuttles, electric power distribution systems operate at different voltage levels owing to the availability of storage devices. Electric motors for traction and fuel cells are connected to a high-voltage bus, whereas batteries and ultracapacitors are mostly connected to a low-voltage bus [6, 7]. A bidirectional DC-DC converter allows transfer of power between two DC sources in either direction. It can reverse the direction of the current flow and thus, the power flow, while keeping the voltage polarity of both source ends unchanged [8]. The charge-discharge current directions change from time to time to perform power conversion. Therefore, the dynamic analysis and control design of a DC-DC converter are very important in improving the performance of the converter system [9-12].

Since small current ripple are not needed in the general charge-discharge system, the requirement can be satisfied with only an LC filter. However, in the case where the internal resistance of the battery and the required current ripple are small, a large-sized filter is required when electrolytic capacitors are used to comprise the LC filter to satisfy the ripple current. If a film capacitor is used, the filter size can be reduced, but it suffers from a problem of increased cost compared with electrolytic capacitors.

$\dagger$ Corresponding Author: Dept. of Electrical and Computer Engineering, Ajou University, Suwon, Korea. (kyl@ajou.ac.kr)

* Dept. of Electrical and Computer Engineering, Ajou University, Suwon, Korea. ( \{skythefly3, jst\}@ajou.ac.kr)

Received: April 2, 2014; Accepted: September 29, 2014
Also, achieving the low current ripple by using an LC filter causes the slower response characteristics due to the increase of capacitance. For this reason, this paper introduces the LCLC filter, adding the inductor and capacitor to the LC filter, which can reduce the filter size and have the fast response characteristics.

To satisfy the required current ripple of the battery $(5 \mathrm{~mA})$ and response time $(10 \mathrm{~ms})$, as listed in Table 1 , this paper presents an LCLC filter design and a dual proportionalintegral (PI)-based control. The dual controller is able to reduce the inner current overshoot by controlling the current flowing through the inner inductor. This will protect the inner circuit. Also, the dual controller has a fast response characteristic when designing large bandwidth in inner controller. The dual current controller consists of two loops from the current of the outer inductor and the output current from the LCLC filter.

Table 1. Required condition

\begin{tabular}{c|c}
\hline Characteristics & Value \\
\hline Response time (-10 to $10 \mathrm{~A})$ & $10 \mathrm{~ms}$ \\
\hline Current ripple of the battery & $5 \mathrm{~mA}$ \\
\hline
\end{tabular}

In this paper, to design a controller for the bidirectional converter, state-space averaging method is used. The averaging techniques provide analytical foundation for most power electronic design procedures at the system level. For pulse-width modulated (PWM) DC-DC converters, the two most popular approaches are the state-space averaging method [13-15] and the circuit average method [16-19]. The state-space averaging method is the most popular approach for modeling of the DC-DC switching converters. State-space averaging and small-signal linearization are key steps in modeling the DC-DC converter. The small-signal transfer functions of nonlinear PWM DC-DC converters are a useful tool for controller design and for 
better understanding of the circuit performance [20]. In the current study, a control model using the state-space averaging method is designed. The state-space averaging method uses this feature to derive the small-signal averaged equation of the PWM switching converters. The advantage of the state-space averaging method is that the results can be generalized. In other words, given a state equation in the original form, the small-signal average model can be obtained [21].

This paper proposes a method to improve the overall performance of the system and is organized as follows: Section 2 presents the design of LCLC filter and control principle of the bidirectional converter. The transfer functions of the interleaved converter with an LCLC filter are derived by using the state-space averaging method. And the design of the dual-loop current controller using the PI controller and the frequency characteristics of the bidirectional converter using the bode plot are discussed. The proposed control model is verified using the PSIM simulation and experiment using a $15-\mathrm{kW}$ battery chargedischarge system, as discussed in Section 3 and 4.

\section{Proposed Improvement Method}

To improve the performance of DC-DC converter for battery charge-discharge system using a conventional LC filter, this paper newly proposes the improvement method. The performance improving method is composed of two parts which are hardware parts, such as power conversion structure and LCLC filter, and software parts, such as a dual controller design using state-space averaging method and frequency characteristics. The proposed bidirectional DC-DC converter system is shown in Fig. 1.

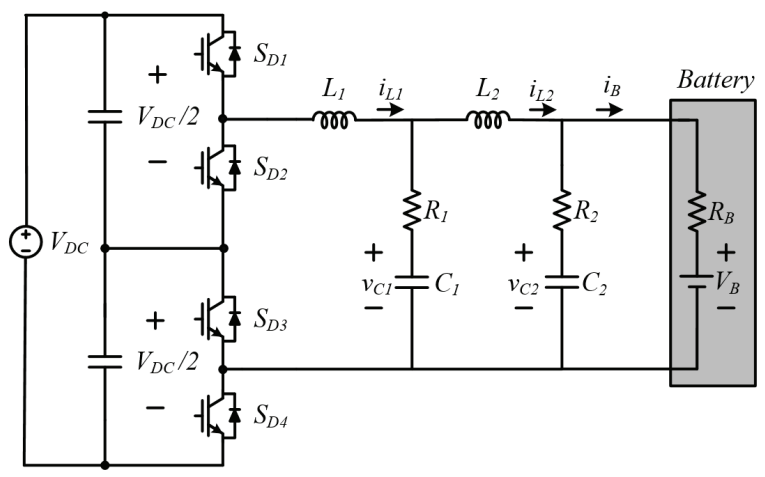

Fig. 1. DC-DC converter system

\subsection{Interleaved model}

A multi-level DC-DC converter with a small voltageunbalanced condition is used in this study. The battery charge-discharge system uses the interleaved method to reduce the ripple of the input current between the battery and the converter and to increase the efficiency. In addition,
Table 2. Converter operating mode

\begin{tabular}{c|c|c|c|c|c}
\hline Mode & $S_{D 1}$ & $S_{D 2}$ & $S_{D 3}$ & $S_{D 4}$ & Converter output voltage \\
\hline 1 & 1 & 0 & 0 & 1 & $V_{D C}$ \\
\hline 2 & 1 & 0 & 1 & 0 & $V_{D C} / 2$ \\
\hline 3 & 0 & 1 & 0 & 1 & $V_{D C} / 2$ \\
\hline 4 & 0 & 1 & 1 & 0 & 0 \\
\hline
\end{tabular}

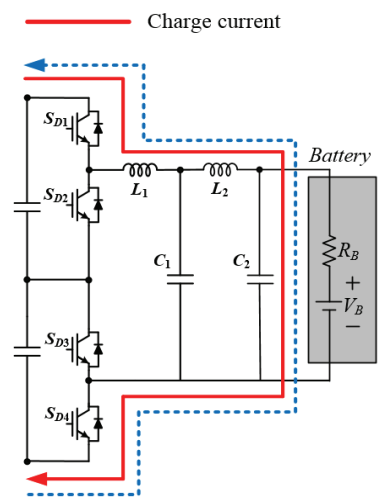

(a)

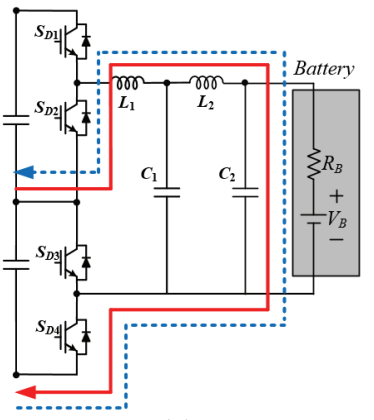

(c)

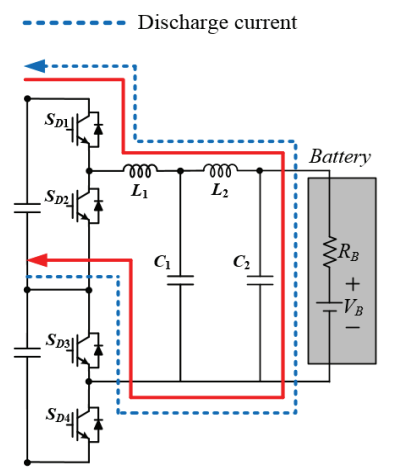

(b)

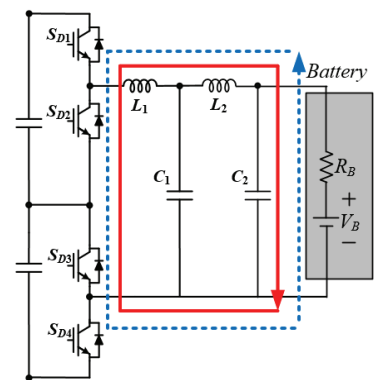

(d)
Fig. 2. Converter operating mode: (a) Mode 1; (b) Mode 2; (c) Mode 3; (d) Mode 4.

the capacitance and size of the converter are reduced. In the interleaved switching, the rated voltage of the switch is lower than that of the two-level switch by $V_{\mathrm{DC}} / 2$ and has twice more effect than the switching frequency.

The DC-DC converter operation is shown in Table 2 and Fig. 2. When the DC-DC converter does not operate interleaved switching, the operating mode of the DC-DC converter is divided in to Mode 1 and Mode 4. The upper switches which are $\mathrm{S}_{D 1}$ and $\mathrm{S}_{D 2}$ operate complementary to each other. The lower switches which are $\mathrm{S}_{D 3}$ and $\mathrm{S}_{D 4}$ also operate complementary to each other. As shown in Table 2, the converter output voltage has only two voltages which are $\mathrm{V}_{D C}$ and 0 . However, when the DC-DC converter operate interleaved switching, the operating mode of the DC-DC converter has four modes which are Mode 1, Mode 2, Mode 3 and Mode 4 in Fig. 2. Also, the output voltage of converter is three types: $\mathrm{V}_{D C}, \mathrm{~V}_{D C} / 2$ and 0 .

Fig. 3 shows waveforms which are carrier, switch signals and line to line voltages depending on the duty. The carrier signal of upper switches and lower switches have a phase difference of 180 degrees in interleaved switching. 


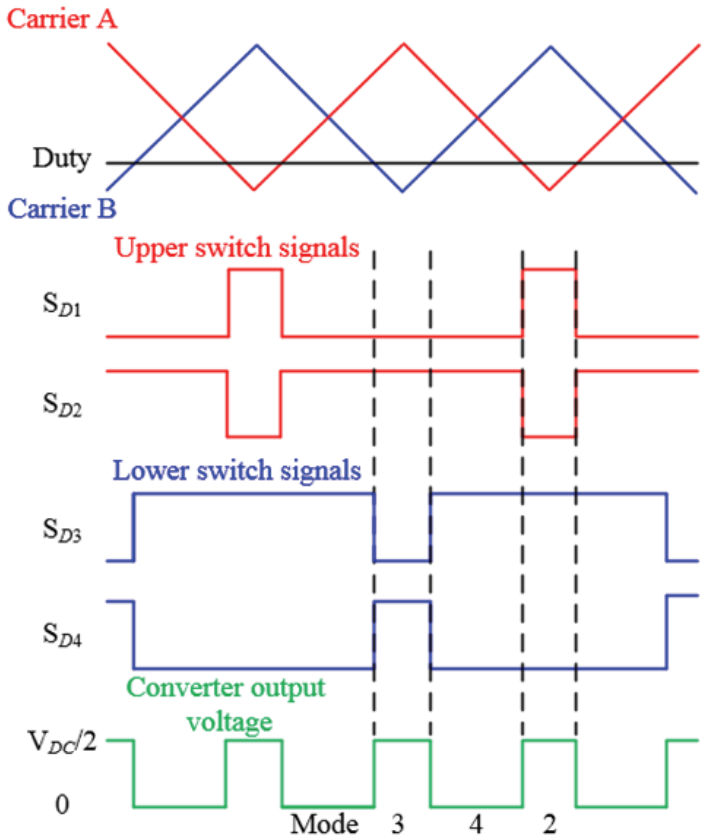

(a)
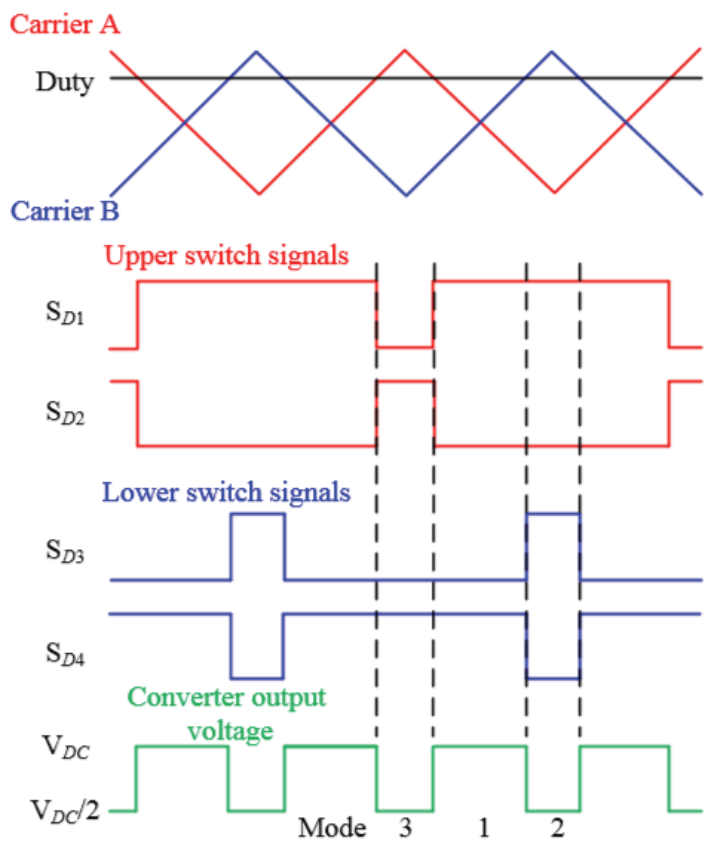

(b)

Fig. 3. Waveforms of interleaved switching depending on (a) $0 \leq$ duty $\leq 0.5$ and (b) $0.5 \leq$ duty $\leq 1$.

Comparing carrier A to duty determines the operation of the upper switch signals. As same manner, comparing carrier B to duty determines the operation of the lower switches.

The proposed interleave switching is divided into two modes of operation depending on the duty cycle. First, when the duty is greater than 0 and less than 0.5 , the DCDC converter operates in Mode 2, 3 and 4 by interleaved switching. At this time, the line to line voltage is 0 or $\mathrm{V}_{D C} / 2$. Second, when the duty is greater than 0.5 and less than 1, the DC-DC converter operates in Mode 1, 3 and 4 by interleaved switching. As shown in Fig. 3 (b), the line to line voltage is $\mathrm{V}_{D C} / 2$ or $\mathrm{V}_{D C}$.

\subsection{Filter design}

LCLC filter is able to reduce the size of the filter and improve the response characteristics. The reason for using the LCLC filter, there are other filters, but LCLC filter is the simplest hardware compared to the LC filter. LCLC filter which is the form with adding $\mathrm{L}$ and $\mathrm{C}$ to $\mathrm{LC}$ filter. To reduce the current ripple, inductor was added. And capacitor was added to the output stage because voltage of DC-DC converter must be controlled same as the output voltage of the battery before connecting the battery.

The LCLC filter is composed of outer inductor $L_{1}$, outer capacitor $C_{1}$, inner inductor $L_{2}$, and inner capacitor $C_{2}$. The internal resistance of the battery must consider the current ripple that flows through the inner capacitor to reduce the current ripple that flows through the battery. $R_{C 1}, R_{C 2}$, and $R_{B}$ are the internal resistances of the outer capacitor, inner capacitor, and battery, respectively. The internal resistance of the battery changes according to the state of chargedischarge, but it is modeled as an average value.

For the filter design, an inductor defines the magnitude of the ripple current that flows in the inductor, and a capacitor defines the magnitude of the output ripple current according to the ratio of the internal resistance of the capacitor and the internal resistance of the battery. It can be expressed as follows:

$$
I_{\text {Battery_ripple }}=I_{\text {Inductor_ripple }} \times \frac{R_{C}}{R_{C}+R_{B}}
$$

For this reason, the internal resistance of the battery and of the capacitor is related to the filter characteristics.

The capacitor voltage changes proportional to the quantity of electric charge flowing in the capacitor. The proportional coefficient, which is $1 / \mathrm{C}$, a large quantity of electric charge is needed to obtain the same amount of voltage variation as the capacitor becomes larger. Therefore, the output response characteristic becomes slower as the quantity of the capacitor becomes larger. Assuming the initial voltage of capacitor is zero, the quantity of electric charge is an integral of the current, it can be expressed as follows:

$$
V_{C}(t)=\frac{1}{C} \int_{t_{0}}^{t} i_{C}(t) d t
$$

When the filter is designed considering the conditions of (1) and (2), if the size of the output capacitor of the filter is increased, the internal resistance of the output capacitor decreases, and the filter can reduce more ripples. However, 
Table 3. Filter parameters

\begin{tabular}{|c|c|c|c|c|c|}
\hline Type & Symbol & Parameters & Value & Size $\mathrm{cm}^{3}$ & Total $\mathrm{cm}^{3}$ \\
\hline \multirow{3}{*}{ LCLC filter } & $\begin{array}{l}L_{1} \\
L_{2}\end{array}$ & $\begin{array}{l}\text { Inner inductor } \\
\text { Outer inductor }\end{array}$ & $\begin{array}{l}6.6 \mathrm{mH} \\
120 \mu \mathrm{H}\end{array}$ & $\begin{array}{c}175.6 \\
12.4\end{array}$ & \multirow{3}{*}{1657.3} \\
\hline & $\begin{array}{r}C_{1} \\
R_{C 1} \\
\end{array}$ & $\begin{array}{c}\text { Inner capacitor } \\
\text { Internal resistance of } C_{1}\end{array}$ & $\begin{array}{l}2.26 \mathrm{mF} \\
58.7 \mathrm{~m} \Omega \\
\end{array}$ & 1425.2 & \\
\hline & $\begin{array}{c}C_{2} \\
R_{C 2} \\
\end{array}$ & $\begin{array}{c}\text { Outer capacitor } \\
\text { Internal resistance of } C_{2}\end{array}$ & $\begin{array}{c}470 \mu \mathrm{F} \\
282 \mathrm{~m} \Omega \\
\end{array}$ & 43.9 & \\
\hline \multirow[b]{2}{*}{ LC filter } & $L$ & Inductor & $6.6 \mathrm{mH}$ & 175.6 & \multirow[b]{2}{*}{3501.1} \\
\hline & $\begin{array}{c}C \\
R_{C}\end{array}$ & $\begin{array}{c}\text { Capacitor } \\
\text { Internal resistance of } C\end{array}$ & $\begin{array}{l}15.19 \mathrm{mF} \\
8.57 \mathrm{~m} \Omega\end{array}$ & 3325.5 & \\
\hline
\end{tabular}

this results induces slow response characteristics of the system. If the size of the output capacitor is small, the internal resistance of the capacitor is larger, the current ripple flows through the battery. For this reason, the LC filter suffers from the limitations of its filter design with a small ripple. In this study, by adding another LC to the LC filter, an LCLC filter is obtained to reduce the size of the filter. The filter design based on the Bessel filter has a maximum flat delay response for control stability.

First, an LCLC filter can be designed as follows. The current ripples at the outer inductor side and the battery side are designed to be $2 \mathrm{~A}$ and $5 \mathrm{~mA}$, respectively. In case of the internal resistance of the battery is $324 \mathrm{~m} \Omega$, the result of the LCLC filter design is listed in Table 3. Next, when designing an LC filter, it is designed to be similar to the LCLC filter design where the ripple current that flows at the outer inductor at $2 \mathrm{~A}$. The capacity of a capacitor is designed considering the internal resistance of the battery and the internal resistance of the capacitor. The result of the LC filter design is shown in Table 3.

By comparing the size and the dynamics of the LCLC filter and the LC filter using the design value, it is as follows. By comparing the inductor size of the two filters, $120 \mu \mathrm{H}$ is used more as the outer inductor, and since it is the smaller size, there are no difference.

By comparing the capacitor, since the LC filter has larger capacitance, it is about twice as much larger than the LCLC filter. By comparing the total filter size, the LCLC filter is $1657.3 \mathrm{~cm}^{3}$ and the LC filter is $3501.1 \mathrm{~cm}^{3}$ which shows that the size of the LCLC filter is about $47.3 \%$ to that of the LC filter. The comparison result of each size is shown in Table 3. Next, by comparing the dynamics of the LCLC filter and the LC filter, if the same current control is performed by implementing each of the designed filter value, the response characteristics is shown as Fig. 4.

The red line in Fig. 4 shows the result that shows the variation for the reference current from $-10 \mathrm{~A}$ to $10 \mathrm{~A}$ at $0.3 \mathrm{~s}$ in the LCLC filter circuit. The blue line in Fig. 4 shows the result when the same reference current is applied in the circuit that use the LC filter. By comparing the two results, the settling time of the current of the blue line in Fig. 4 lags $0.1 \mathrm{~s}$ behind redline in Fig. 4. Even though the ripple current that flows through inductors in the LCLC filter and in the LC filter are identical, which makes the

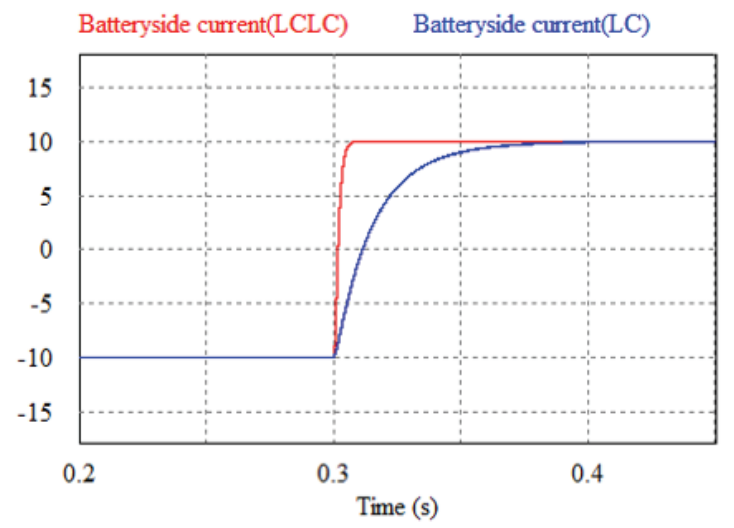

Fig. 4. Response characteristics of the LCLC and LC filter

same amount of electric charge to flow into the output capacitor and the battery, the two waveforms show some difference due to the difference of the output capacitance. As shown in (2), in the case of the LCLC filter, the output capacitance is small which makes the voltage to be easily changed with the low electric charge; on the other hand in the case of the LC filter, due to the fact that the output capacitance is large, the variation of the voltage occurs slower than the LCLC filter if the identical quantity of electric charge is absorbed. Since the output voltage changes slowly, the response characteristics of the output current can become slower as well. For this reason, this paper proposes the controller design that uses the LCLC filter which reduces the size while possessing the fast response characteristics.

\subsection{State-space averaging method}

The state-space description is a canonical form of writing the differential equations that describe a system. In the linear network, the derivative of the state variables can be expressed as a linear combination of the independent input of the system and the state variables themselves [18]. The state-space averaging method is based on the consideration of two different mathematical models and produces only one model with the same properties of each model. These two models are based on the switching states.

To derive the proper dynamic equation of the bidirectional 
DC-DC converter, state variables composed of the inductor currents and capacitor voltages are needed.

In the bidirectional DC-DC converter using the LCLC filter, four state variables are present: two inductor currents and two capacitor voltages. Four equations are applied to the state-space averaging method: two node equations and two loop equations. The state equation of the system can be expressed as simple matrices as follow:

$$
\begin{gathered}
\frac{d}{d t} x=A x+B u \\
y=C x+E u .
\end{gathered}
$$

State vector $\mathrm{x}$ is a vector containing all the state variables, which are the inductor currents and capacitor voltages. Input vector $\mathrm{u}$ contains the independent input parameters to the system, which are the DC-link and battery voltages. Vector $\mathrm{y}$, which is an output vector, can be freely selected. In this system, to model the current flowing through the battery, the system requires the battery-side current. Therefore, output vector y sets the current equation on the battery side. The state vectors are as follow:

$$
x=\left[\begin{array}{llll}
i_{L 1} & i_{L 2} & v_{C 1} & v_{C 2}
\end{array}\right]^{T}, \quad u=\left[\begin{array}{ll}
v_{D C} & v_{B}
\end{array}\right]^{T}, y=\left[i_{B}\right] .
$$

In the system, the applied switch mode is determined by the output voltages. Therefore, modeling according to the ON/OFF states of the switches, such as the two-level system, is impossible. Thus, to distinguish the two switching states, the switching state that produces a relatively high voltage is termed as "HIGH," whereas the switching state that produces a low voltage is termed as "LOW."

The modeling must be classified into two cases: when the battery voltage is smaller than half of the DC-link voltage and when it is larger than half of the DC-link voltage. When the battery voltage is smaller than half of the DC-link voltage, the output voltage is produced by applying two capacitor voltages and a zero voltage; the $\mathrm{HIGH}-$ switching state corresponds to Modes 2 and 3 in Fig. 2, whereas the LOW-switching state corresponds to Mode 4. When the battery voltage is larger than half of the DC-link voltage, the output voltage is produced by applying the DC-link voltage and two capacitor voltages; the HIGH-switching state corresponds to Mode 1 in Fig. 2, whereas the LOW-switching state corresponds to Modes 2 and 3 in Fig. 2. This study deals only with the case where the battery voltage is smaller than half of the DClink voltage.

Because the circuit is connected in different manners according to the states of the switches, the matrix of each state equation must be defined into two states in such a manner that each state can be described by $A_{1}, B_{1}, C_{1}$, and $E_{1}$ and $A_{2}, B_{2}, C_{2}$, and $E_{2}$.

When the switching state is HIGH, the inductor currents, capacitor voltages, and output battery current are expressed as

$$
\begin{gathered}
v_{C 1}=\frac{v_{D C}}{2}-L_{1} \frac{d i_{L 1}}{d t}-C_{1} R_{1} \frac{d v_{C 1}}{d t} \\
i_{L 1}=i_{L 2}+C_{1} \frac{d v_{C 1}}{d t} \\
v_{C 2}=v_{C 1}+C_{1} R_{1} \frac{d v_{C 1}}{d t}-L_{2} \frac{d i_{L 2}}{d t}-C_{2} R_{2} \frac{d v_{C 2}}{d t} \\
i_{L 2}=\frac{v_{C 2}+C_{2} R_{2} \frac{d v_{C 2}}{d t}-v_{B}}{R_{B}}+C_{2} \frac{d v_{C 2}}{d t} \\
i_{B}=\frac{v_{C 2}+R_{2} C_{2} \frac{d v_{C 2}}{d t}-v_{B}}{R_{B}} .
\end{gathered}
$$

These equations can be written in the following statespace form when the switching state is HIGH:

$$
\begin{gathered}
\frac{d}{d t} x=A_{1} x+B_{1} u \\
y=C_{1} x+E_{1} u .
\end{gathered}
$$

The state-equation matrices are expressed as (13) (shown in the Appendix).

When the switching state is LOW, the inductor currents, capacitor voltages, input DC voltage, and output battery current are

$$
\begin{gathered}
v_{C 1}=-L_{1} \frac{d i_{L 1}}{d t}-C_{1} R_{1} \frac{d v_{C 1}}{d t} \\
i_{L 1}=i_{L 2}+C_{1} \frac{d v_{C 1}}{d t} \\
v_{C 2}=v_{C 1}+C_{1} R_{1} \frac{d v_{C 1}}{d t}-L_{2} \frac{d i_{L 2}}{d t}-C_{2} R_{2} \frac{d v_{C 2}}{d t} \\
i_{L 2}=\frac{v_{C 2}+C_{2} R_{2} \frac{d v_{C 2}}{d t}-v_{B}}{R_{B}}+C_{2} \frac{d v_{C 2}}{d t} \\
i_{B}=\frac{v_{C 2}+R_{2} C_{2} \frac{d v_{C 2}}{d t}-v_{B}}{R_{B}} .
\end{gathered}
$$

These equations can be written in the following statespace form when the switching state is LOW:

$$
\begin{gathered}
\frac{d}{d t} x=A_{2} x+B_{2} u \\
y=C_{2} x+E_{2} u .
\end{gathered}
$$

The state-equation matrices are expressed as (21) (shown in the Appendix).

The two switching state-equations are averaged using the duty ratio as a weighting factor. When the switching state is HIGH, (11) and (12) are multiplied by the HIGH duty ratio $d_{1}$; when the switching state is LOW, (19) and (20) are multiplied by the LOW duty ratio $d_{2}$. Eqs. (22) and (23) can be obtained by adding these two values. 


$$
\begin{gathered}
\frac{d}{d t} x=\left(A_{1} d_{1}+A_{2} d_{2}\right) x+\left(B_{1} d_{1}+B_{2} d_{2}\right) u \\
y=\left(C_{1} d_{1}+C_{2} d_{2}\right) x+\left(E_{1} d_{1}+E_{2} d_{2}\right) u
\end{gathered}
$$

To derive the DC model, the DC terms are set to zero. The state-space averaged model that describes the converter in equilibrium is expressed as

$$
\begin{aligned}
& 0=A X+B U \\
& Y=C X+E U
\end{aligned}
$$

where the averaged matrices are expressed as (26) (shown in the Appendix).

Eqs. (24) and (25) can be solved to find the equilibrium state and output vectors, which are expressed as (27) and (28) (shown in the Appendix). The DC model yields the DC information (steady-state behavior) and can be used for the loss estimation.

To construct a small-signal AC model at a quiescent operating point, each vector is composed of the equilibrium $\mathrm{DC}$ components and $\mathrm{AC}$ variations.

$$
\begin{aligned}
& x=X+\hat{x}, \quad y=Y+\hat{y}, \quad u=U+\hat{u}, \\
& d_{1}=D_{1}+\hat{d}_{1}, \quad d_{2}=D_{2}+\hat{d}_{2} .
\end{aligned}
$$

Here, $X, Y, U, D_{1}$, and $D_{2}$ are the equilibrium DC components in the quiescent operating point, and $\hat{x}, \hat{y}$, $\hat{u}, \hat{d}_{1}$, and $\hat{d}_{2}$ are the small AC variations. By assuming that the small AC variations are much smaller than the DC components, the nonlinear converter equations can be linearized. The substitution of (22) and (23) into (29) yields the following:

$$
\begin{aligned}
& \frac{d}{d t}(X+\hat{x})=\left(A_{1} d_{1}+A_{2} d_{2}\right)(X+\hat{x})+\left(B_{1} d_{1}+B_{2} d_{2}\right)(U+\hat{u}) \\
& (Y+\hat{y})=\left(C_{1} d_{1}+C_{2} d_{2}\right)(X+\hat{x})+\left(E_{1} d_{1}+E_{2} d_{2}\right)(U+\hat{u}) .
\end{aligned}
$$

To obtain the AC model (small-signal) equation, we neglect the nonlinear product terms $\hat{d} \cdot \hat{x}$ and $\hat{d} \cdot \hat{u}$. The AC model equations are expressed as (32) and (33).

$$
\begin{gathered}
\frac{d}{d t} \hat{x}=A \hat{x}+B \hat{u}+F \hat{d} \\
\hat{y}=C \hat{x}+E \hat{u}+G \hat{d}
\end{gathered}
$$

where

$$
\begin{aligned}
& F=\left(A_{1}-A_{2}\right) X+\left(B_{1}-B_{2}\right) U \\
& G=\left(C_{1}-C_{2}\right) X+\left(E_{1}-E_{2}\right) U .
\end{aligned}
$$

The $A, B, C$, and $E$ terms are same as those in (26) (shown in the Appendix).

We transform the AC state-space model into the frequency domain (Laplace transform and s-domain). The hats above the variables are neglected for simplicity. The small signal of a variable is denoted using a lower-case letter. The dynamic equations are as follows:

$$
\begin{gathered}
\frac{d}{d t} x=A x+B u+F d \\
y=C x+E u+G d .
\end{gathered}
$$

The Laplace transform of (36) is expressed as

$$
s x(s)=A x(s)+B u(s)+F d(s) .
$$

Simplifying (38) yields

$$
\begin{aligned}
x(s) & =(s I-A)^{-1} B u(s)+(s I-A)^{-1} F d(s) \\
& =H_{u}(s) u(s)+H_{d}(s) d(s) .
\end{aligned}
$$

From (39), we can derive the following:

$$
\begin{aligned}
& H_{u}(s)=\frac{x(s)}{u(s)}=(s I-A)^{-1} B \\
& H_{d}(s)=\frac{x(s)}{d(s)}=(s I-A)^{-1} F .
\end{aligned}
$$

The substitution of (5) into (39) yields the following transfer functions shown in matrix form:

$$
\left[\begin{array}{l}
i_{L 1} \\
i_{L 2} \\
V_{C 1} \\
V_{C 2}
\end{array}\right]=\left[\begin{array}{ll}
H_{u 11}(s) & H_{u 12}(s) \\
H_{u 21}(s) & H_{u 22}(s) \\
H_{u 31}(s) & H_{u 32}(s) \\
H_{u 41}(s) & H_{u 42}(s)
\end{array}\right]\left[\begin{array}{l}
v_{D C} \\
v_{B}
\end{array}\right]+\left[\begin{array}{c}
H_{d 1}(s) \\
H_{d 2}(s) \\
H_{d 3}(s) \\
H_{d 4}(s)
\end{array}\right] d .
$$

Eq. (40) shows that matrices $H_{u}(s)$ indicate the transfer functions of the independent input-to-state variables $\left[\left(v_{D C}\right.\right.$ and $\left.v_{B}\right)$ to $\left(i_{L 1}, i_{L 2}, v_{C 1}\right.$ and $\left.\left.v_{C 1}\right)\right]$. The matrix $H_{d}(\mathrm{~s})$ shows the transfer functions of the control-to-state variables (d).

The dynamic equation, namely, (37), can be evaluated in a similar manner. The Laplace transform of (37) is expressed as

$$
y(s)=C x(s)+E u(s)+G d(s)
$$

The substitution of (39) into (43) yields the following:

$$
\begin{aligned}
y(s) & =\left[C(s I-A)^{-1} B+E\right] u(s)+\left[C(s I-A)^{-1} F+G\right] d(s) \\
& =G_{u}(s) u(s)+G_{d}(s) d(s) .
\end{aligned}
$$

From (44) and (45), we can derive the following:

$$
\begin{aligned}
& G_{u}(s)=\frac{y(s)}{u(s)}=C(s I-A)^{-1} B+E \\
& G_{d}(s)=\frac{y(s)}{d(s)}=C(s I-A)^{-1} F+G .
\end{aligned}
$$

The substitution of (5) into (45) yields the following transfer functions shown in matrix form: 


$$
\left[i_{B}\right]=\left[\begin{array}{l}
G_{u 1}(s) \\
G_{u 2}(s)
\end{array}\right]\left[\begin{array}{l}
v_{D C} \\
v_{B}
\end{array}\right]+\left[G_{d}(s)\right] d
$$

Eq. (46) indicates that matrices $G_{u}(\mathrm{~s})$ show the transfer functions of the independent input-to-battery current $\left(i_{B}\right)$. Matrix $G_{d}(\mathrm{~s})$ shows the transfer functions of the controlto-battery current. In this paper, the double-loop current controller composed of the inner and outer current controllers is presented. The transfer function of the outer current controller is $H_{d 1}(\mathrm{~s})$, which is the first row of matrix $H_{d}(\mathrm{~s})$ because the outer current controller controls the current flowing through the outer inductor. The internal resistance of the battery and capacitors are considered for designing accurate controller. When designing the current controller, internal resistances have an influence on current control. For this reason, internal resistances must be considered in designing the current controller. The transfer function of the outer current controller is $H_{d 1}(\mathrm{~s})$ and is expressed as (49). The transfer function of the inner current controller is $G_{d}(\mathrm{~s})$ and is expressed as (50).

\subsection{Dual current controller}

The controller is designed as a dual current controller, which can operate stably on the basis of the calculated transfer function using the state-average equation. Fig. 5 shows that the dual current control method can be composed by adding the outer current controller to the inner current controller. In designing the controller, we first design it as an inner current controller, which is not affected by the switching frequency. We also design it to have an adequate phase margin. The outer current controller is composed by adding the outer current controller to the inner current controller, and we design the crossover frequency so that the inner current controller is not affected.

The block diagram of the DC-DC converter system is

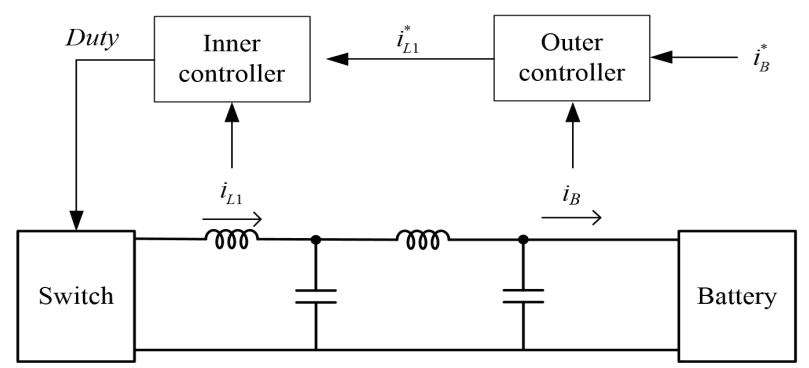

Fig. 5. Dual current controller system

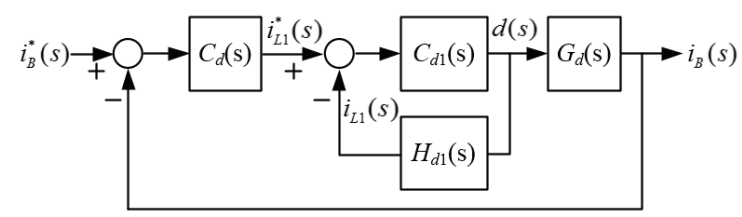

Fig. 6. Block diagram of dual current controller shown in Fig. 6. Using the state-space averaging method, a stable dual current controller can be designed. The block diagram of the converter system is composed of the battery current $\left(i_{\mathrm{B}}\right)$, duty cycle $(\mathrm{d})$ which is 'ON' time of switch $\mathrm{S}_{D 1}$ and $\mathrm{S}_{D 4}$ in Fig. 2, outer inductor current $\left(i_{L 1}\right)$, transfer function of the control-to-battery current $\left(G_{d}(\mathrm{~s})\right)$, transfer function of the control-to-outer inductor current $\left(H_{d 1}(\mathrm{~s})\right)$, PI controller of the outer current $\left(C_{d}(\mathrm{~s})\right)$, and PI controller of the inner current $\left(C_{d 1}(\mathrm{~s})\right)$.

The received reference battery current passes through the PI controller. The inner current controller receives the reference current from the outer current controller as an input. Then, the inner current controller determines the duty. The duty passes through the transfer function, and the system finally outputs the battery current.

The dual current controller needs two transfer functions: control-to-outer inductor current and control-to-battery current. $H_{d l}(\mathrm{~s})$ and $G_{d}(\mathrm{~s})$ can be calculated by (47) and (48) (shown in the Appendix).

The proposed current controller uses a dual current controller in the battery charge-discharge system. Using the dual current controller increases the complexity of the controller design but yields fast dynamic characteristics owing to the large bandwidth. The dual current controller process is described as follows: initially, the current control loop, which is an inner loop, is designed. While the stability of the controller is maintained, the battery current controller is designed as the outer loop to realize the required performance.

To verify the dynamic response of the designed controller, the frequency characteristics are analyzed. The frequency characteristics for the open-loop transfer function obtained in (41) and (47) are analyzed. The parameters of the system are listed in Table 4. Fig. 7 shows the frequency characteristic of the inner current controller. The red line shows the bode plot of $H_{d 1}(\mathrm{~s})$. As shown in Fig. 7, the $H_{d 1}(\mathrm{~s})$ transfer function characteristic is stable, but the cross frequency is $20 \mathrm{kHz}$, which is too high to be affected by the switching ripple. For this reason, by adding PI controller $C_{i}(\mathrm{~s})$, the system can obtain the required characteristics. The blue line shows the bode plot of $H_{d 1}(\mathrm{~s})$ multiplied by $C_{d 1}(\mathrm{~s})$. The system design of the phase margin is $88^{\circ}$, and the crossover frequency of $2 \mathrm{kHz}$ does not affect the switching frequency.

Output current is affected by the internal resistance of the battery and the output capacitor. For this reason, the internal resistance of the battery of the transfer function should be included. The internal resistance of the battery varies depending on the charging state of the battery. However, even if there is changing of the internal resistance of battery, the stability of DC-DC converter system must be maintained. For this reason, when there is a changing in the internal resistance of battery, the stability of the inner current controller was verified. In this paper, the changing of internal resistance of battery was set to $30 \%$. The green dotted line shows the result of frequency 
characteristic in case of $30 \%$ increasing of internal resistance of battery. The yellow dotted line shows the result of frequency characteristic in case of $30 \%$ decreasing of internal resistance of battery. As shown Fig. 7, even if the internal resistance of the battery is changed, the stability of inner current controller was maintained.

Fig. 8 shows the frequency characteristics of the outer current controller. The red line shows the bode plot of $G_{d}(\mathrm{~s})$. As shown in this figure, the $G_{d}(\mathrm{~s})$ transfer function characteristic is stable, but the cross frequency is almost

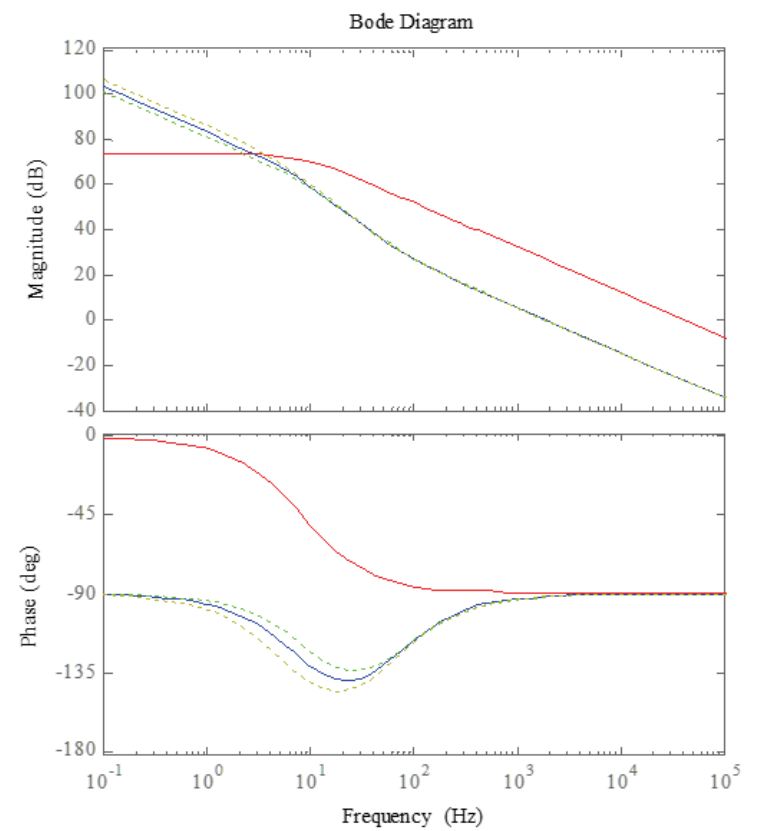

Fig. 7. Frequency characteristic of the system. Bode plot of inner current controller.

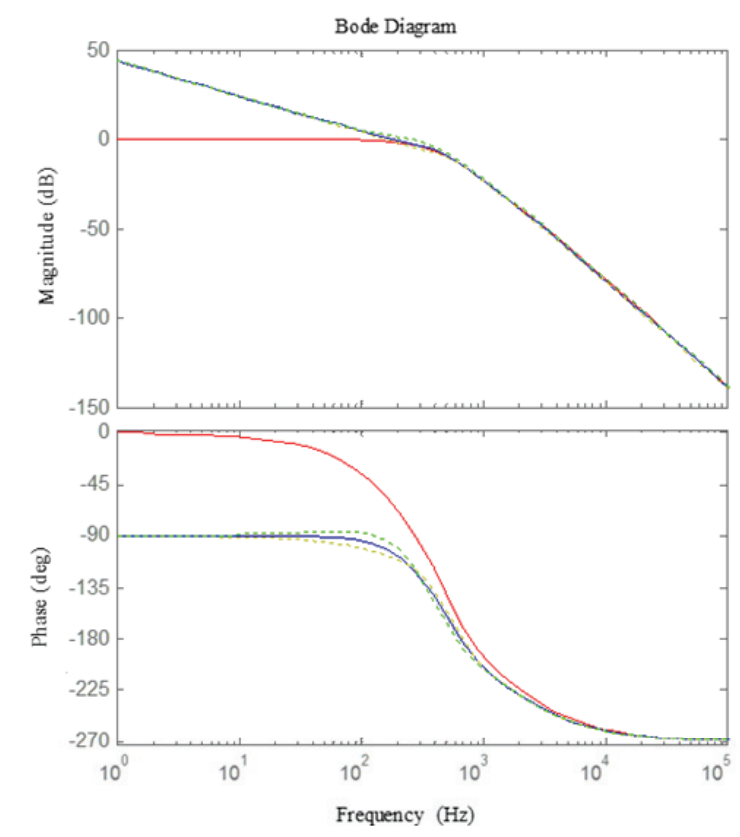

Fig. 8. Frequency characteristic of the system. Bode plot of outer current controller
$0 \mathrm{~Hz}$, which is too small for fast response characteristics. Therefore, by adding PI controller $C_{d}(\mathrm{~s})$, the system can obtain the required characteristics. The solid line shows the bode plot of outer controller multiplied by $C_{d}(\mathrm{~s})$. To obtain a stable operation, the system must have not only a sufficient phase margin but also a gain margin in the region so that it cannot be affected by other control frequencies. For these reasons, the system design of the phase margin is $73^{\circ}$, and the crossover frequency of 200 $\mathrm{Hz}$ does not affect the inner current controller. Similar to Fig. 7, the green dotted line shows the result of frequency characteristic in case of $30 \%$ increasing of internal resistance of battery. The yellow dotted line shows the result of frequency characteristic in case of 30\% decreasing of internal resistance of battery. In case of changing the resistance of the battery, the stability of the outer current controller was verified through the bode plot.

\section{Simulation results}

To confirm the validity of the proposed algorithm, a simulation was performed using the PSIM software, performed under the conditions listed in Tables 3 and Table 4.

The system switches twice in one period because of the interleaved switching. The response time must be under 10

Table 4. Circuit parameters

\begin{tabular}{c|c|c}
\hline Symbol & Parameters & Value \\
\hline$V_{D C}$ & Input DC voltage & $1650 \mathrm{~V}$ \\
\hline$V_{B}$ & Output battery voltage & $330 \mathrm{~V}$ \\
\hline$R_{B}$ & Internal resistance of the battery & $324 \mathrm{~m} \Omega$ \\
\hline$f_{S W}$ & Switching frequency & $7.8 \mathrm{kHz}$ \\
\hline$L_{1}$ & Inner inductor & $6.6 \mathrm{mH}$ \\
\hline$L_{2}$ & Outer inductor & $120 \mu \mathrm{H}$ \\
\hline$C_{1}$ & Inner capacitor & $2.26 \mathrm{mF}$ \\
\hline$R_{C 1}$ & Internal resistance of $\mathrm{C}_{1}$ & $58.7 \mathrm{~m} \Omega$ \\
\hline$C_{2}$ & Outer capacitor & $470 \mu \mathrm{F}$ \\
\hline$R_{C 2}$ & Internal resistance of $\mathrm{C}_{2}$ & $282 \mathrm{~m} \Omega$ \\
\hline
\end{tabular}

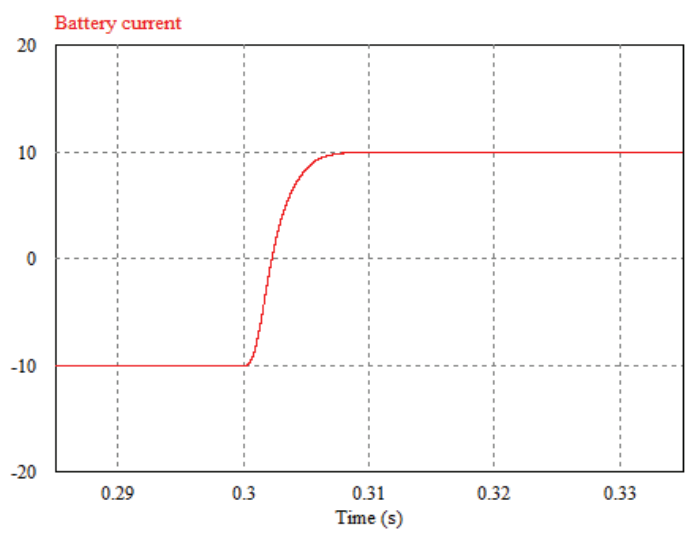

Fig. 9. Simulation result of transient response depending on current change from -10 to $10 \mathrm{~A}$ when using LCLC filter 
ms. In addition, the current ripple of the outer inductor must not be more than $2 \mathrm{~A}$, and the current ripple of the battery should not be more than $5 \mathrm{~mA}$.

Fig. 9 shows the simulation result that shows the variation for the reference current from $-10 \mathrm{~A}$ to $10 \mathrm{~A}$ when using LCLC filter circuit. The blue line in Fig. 10 shows the simulation result when the same reference current is applied in the circuit when using LC filter. By comparing the two results, the settling time of the battery current in Fig. 9 is $8 \mathrm{~ms}$ but settling time of battery current in Fig. 10 is $1 \mathrm{~s}$. As described in Section 2, the difference of settling time of the battery current is generated by the difference between the capacitance of LCLC filter and LC filter. The output capacitance of LCLC filter is much smaller than the output capacitance of LC filter which makes the voltage to be easily changed. Since these reasons, the response characteristics of the output current can become slower.

Fig. 11 shows the simulation result when the current reference changes from 10 to $-10 \mathrm{~A}$ in the LCLC filter circuit. Fig. 12 shows the simulation result when the same

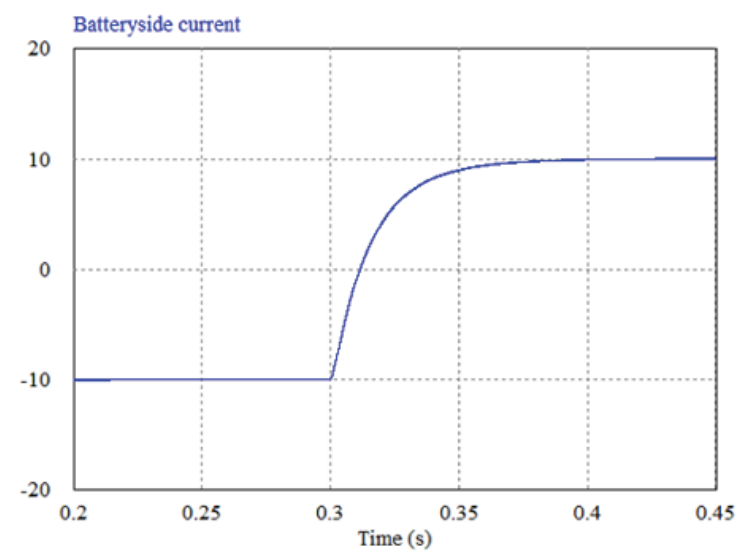

Fig. 10. Simulation result of transient response depending on current change from -10 to $10 \mathrm{~A}$ when using LC filter

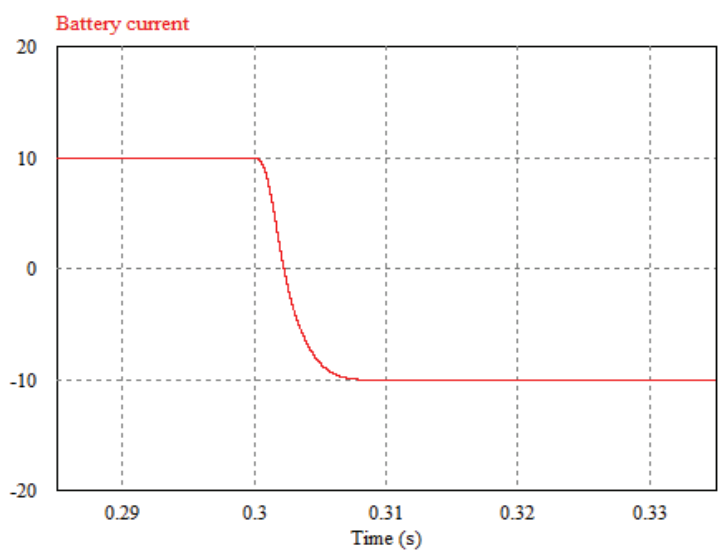

Fig. 11. Simulation result of transient response depending on current change from 10 to -10 A when using LCLC filter reference current is applied in the circuit when using LC Fig. 13 shows the current ripple of the outer inductor and the output voltage of the DC-DC converter. The upper line shows the current ripple of the outer inductor. The lower line shows the output voltage of the DC-DC converter. We

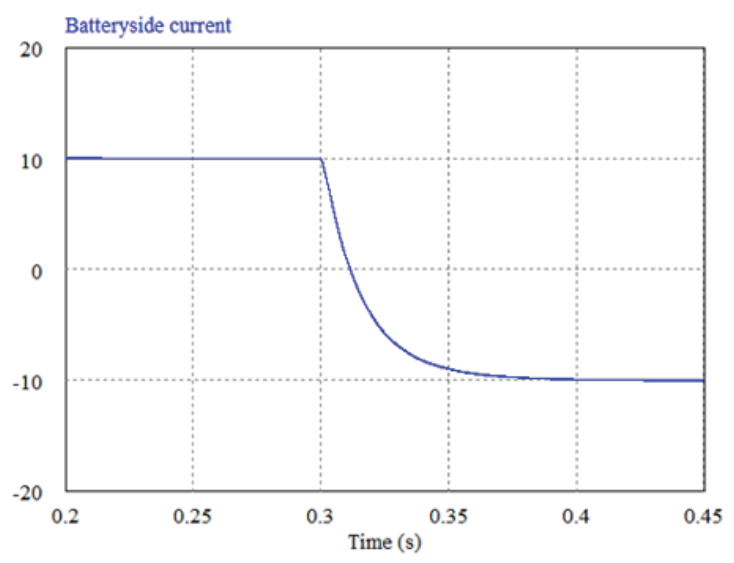

Fig. 12. Simulation result of transient response depending on current change from 10 to -10 A when using LC filter

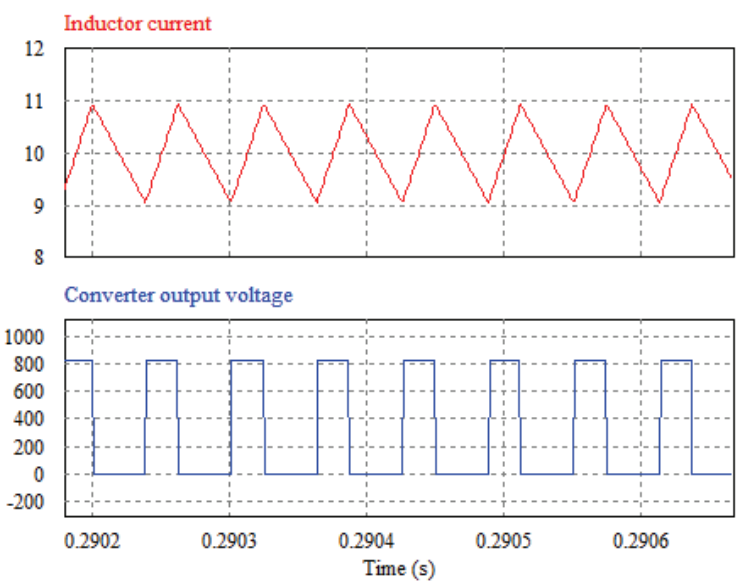

Fig. 13. Simulation results of current ripple of inductor and converter output voltage

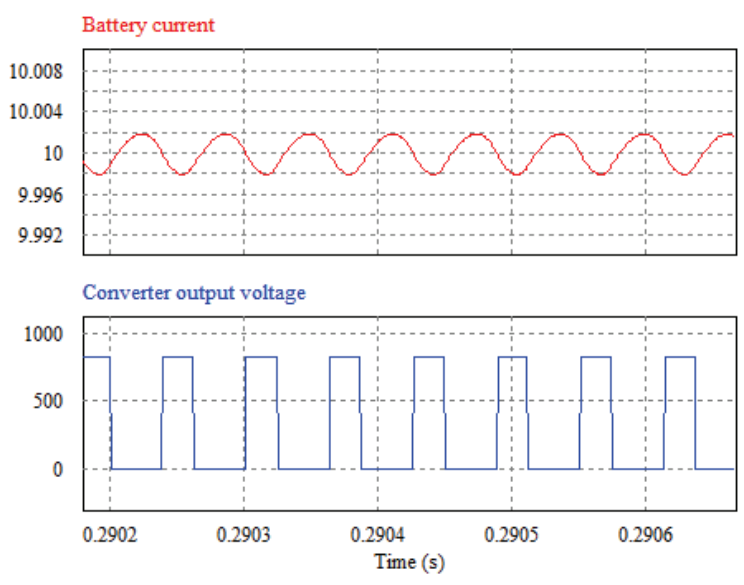

Fig. 14. Simulation results of current ripple of battery and converter output 
can see that switching is performed twice during one period, and the peak-to-peak value of the current ripple is within 2 A during the DC-DC converter switching. The output voltage is produced by applying the two capacitor voltages $(825 \mathrm{~V})$, which is half of the DC-link voltage $(1650 \mathrm{~V})$, and the zero voltage because the battery voltage $(330 \mathrm{~V})$ is smaller than half of the DC-link voltage.

Fig. 14 shows the current ripple of the battery and the output voltage of the DC-DC converter. The upper line shows the current ripple of the outer inductor. Similar to that shown in Fig. 11, we can see that switching is performed twice during one period, and the output voltage is produced by applying the two capacitor voltages and the zero voltage. The current ripple of the battery is within 5 $\mathrm{mA}$, as designed.

\section{Experimental results}

The bidirectional DC-DC converter battery charge discharge system is shown in Fig. 15. The proposed method

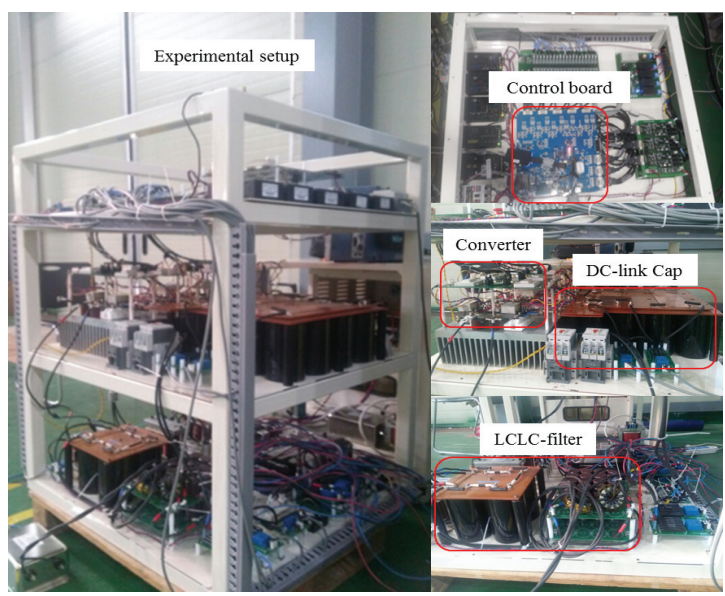

Fig. 15. Experimental setup for battery charge-discharge system

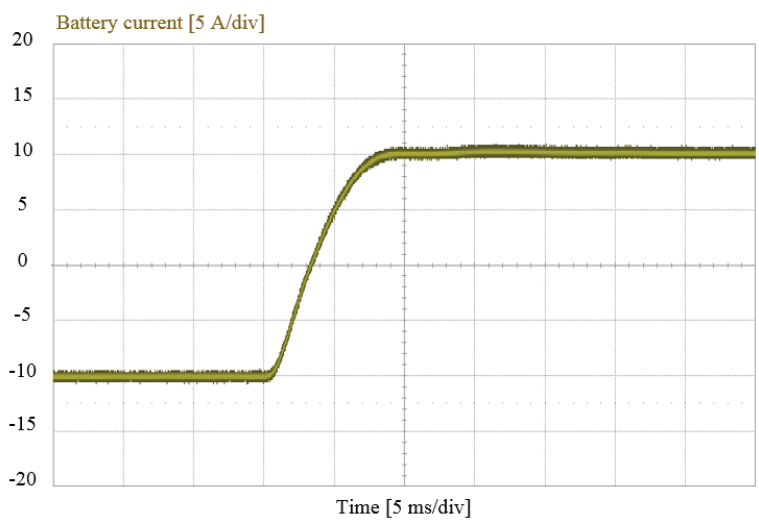

Fig. 16. Experimental result of transient response depending on current change from -10 to 10 A when using LCLC filter is programmed on a TM320F28346 digital signal processor. The experimental conditions are the same as those in the simulation.

Fig. 16 shows the experimental results when using LCLC filter that shows the variation for the reference current from -10 to $10 \mathrm{~A}$. And Fig. 17 show the experimental results when same as current control in LC filter is performed. By comparing the case of when using LCLC filter and LC filter, the settling time in Fig. 16 is $8 \mathrm{~ms}$ but the settling time in Fig. 17 is $1 \mathrm{~s}$ in the same current ripple condition. These are the same results that were confirmed through the simulation in Section 3.

Fig. 18 shows the experimental result when the current reference changes from 10 to $-10 \mathrm{~A}$ in the LCLC filter circuit. Fig. 19 shows the experimental result when the same reference current is applied in the circuit when using LC filter. The yellow line shows the battery current; when using LCLC filter, the settling time in Fig. 18 is $8 \mathrm{~ms}$ but when using LC filter, the settling time in Fig. 19 is $1 \mathrm{~s}$. The experimental results show that LCLC filter has the faster response characteristics than LC filter on both the rising period and falling period of the battery current.

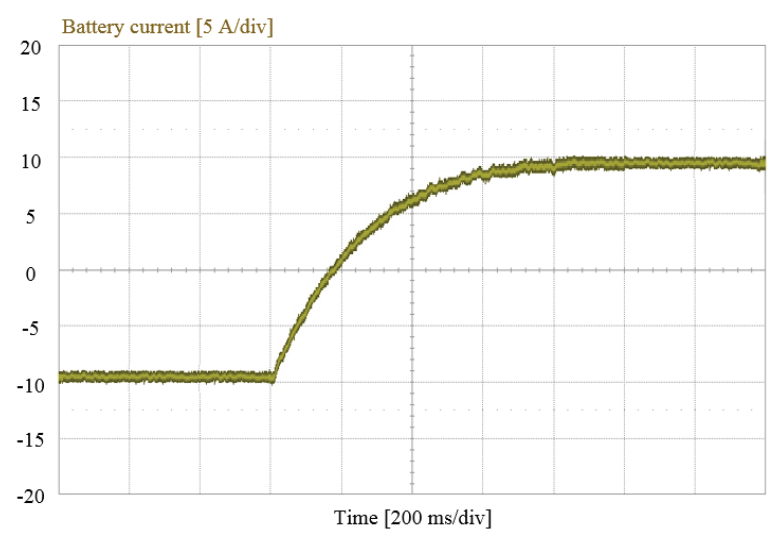

Fig. 17. Experimental result of transient response depending on current change from -10 to 10 A when using LC filter

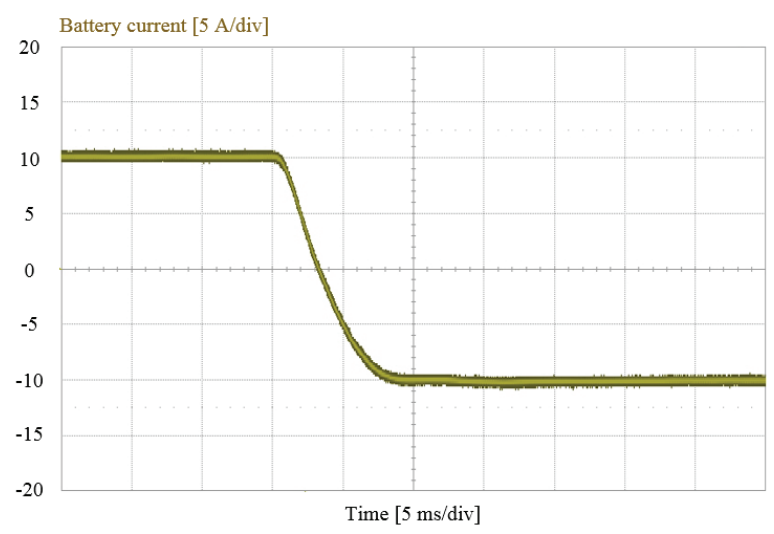

Fig. 18. Experimental result of transient response depending on current change from 10 to -10 A when using LCLC filter 


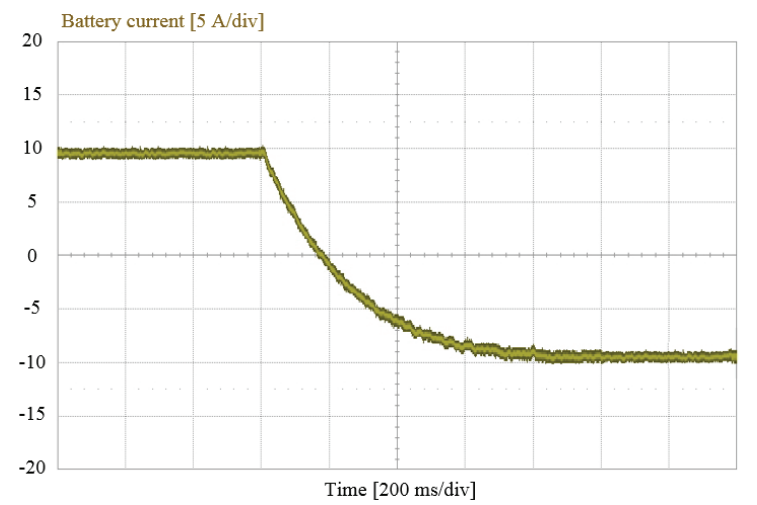

Fig. 19. Experimental result of transient response depending on current change from 10 to -10 A when using LC filter

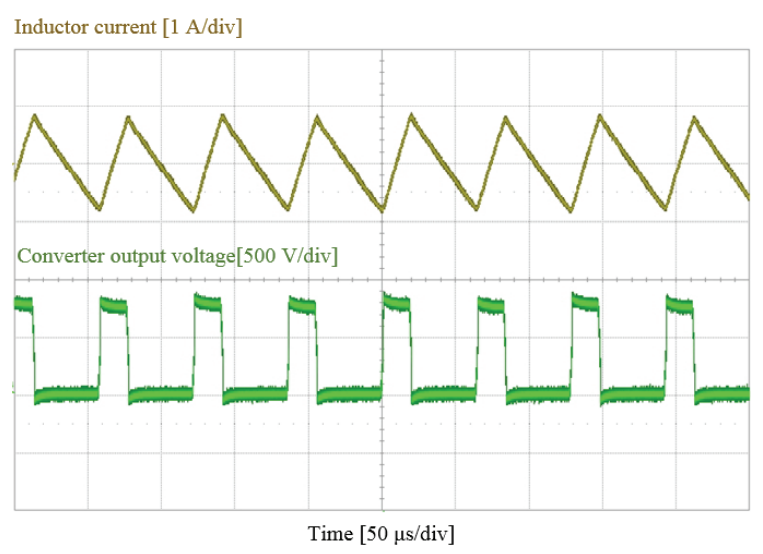

Fig. 20. Experimental results of current ripple of inductor and converter output voltage

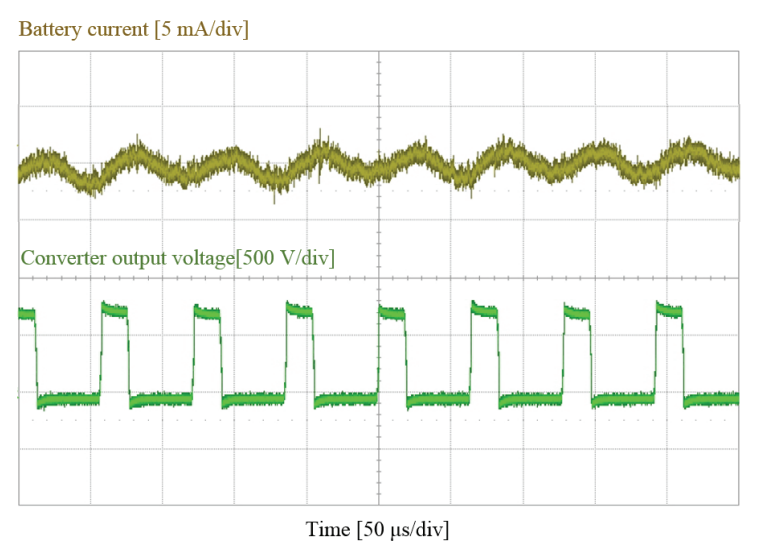

Fig. 21. Experimental results of current ripple of battery and converter output voltage

Fig. 20 shows the current ripple of the outer inductor and the output voltage of the DC-DC converter. The upper line shows the current ripple of the outer inductor. The lower line shows the output voltage of the DC-DC converter. Similar to the simulation result, we can see that switching is performed twice during one period, and the peak-to-peak value of the current ripple is within $2 \mathrm{~A}$. The output voltage is produced by applying the two capacitor voltages and the zero voltage. Fig. 21 shows the current ripple of the battery and the output voltage of the DC-DC converter. The upper line shows the current ripple of the outer inductor. We can see that switching is done twice during one period, and the current ripple is within $5 \mathrm{~mA}$, as designed.

\section{Conclusion}

This paper has presented the method to improve the performance of the charge-discharge system that uses the LCLC filter. In the general battery charge-discharge system using LC filter, in case of the internal resistance of the battery and requested current ripple is small that induce the larger size of the filter. To solve this problem, this paper presents the system using interleaved switching and LCLC filter which reduces the size while possessing the fast response characteristics.

The simulation results show that the system using the frequency characteristics is stable and satisfies the required dynamic characteristics and current ripples. The effectiveness of the designed controller and the LCLC filter was verified by the experimental results.

\section{Acknowledgements}

This work was supported by the Human Resources Development program (No. 20134030200310) of the Korea Institute of Energy Technology Evaluation and Planning (KETEP) grant funded by the Korea government Ministry of Knowledge Economy.

This research was supported by Basic Science Research Program through the National Research Foundation of Korea (NRF) funded by the Ministry of Education (No. 2013R1A1A2A10006090).

\section{References}

[1] J.H. Park, H.G. Jeong, and K.B. Lee, "Output Current Ripple Reduction Algorithms for Home Energy Storage System," Energies, vol. 6, no. 10, pp. 55525569, Sep. 2013.

[2] J. H. Park, H. G. Jeong, and K. B. Lee, "Second Order Harmonics Reduction Technique Using Model Predictive Control for Household Energy Storage Systems," in Proceedings of Applied Power Electronics Conference and Exposition, pp. 3060-3065, Mar. 2014.

[3] F. Z. Peng, H. Li, G. J. Su, and J. S. Lawler, "A New ZVS Bidirectional DC- DC Converter for Fuel Cell and Battery Application," IEEE Trans. Power Electronics, vol. 19, no. 1, pp. 54-65, Jan. 2011.

[4] D. J. Lee, and L. Wang, "Small-Signal Stability Analysis of an Autonomous Hybrid Renewable Energy 
Power Generation/Energy Storage System Part I: Time-Domain Simulations," IEEE Trans. Energy Conversion, vol. 23, no. 1, pp. 311-320, Mar. 2008.

[5] S. Yang, K. Goto, Y. Imamura, and M. Shoyama, "Dynamic Characteristics Model of Bi-directional DCDC Converter using State-Space Averaging Method," in Proceedings of Telecommunications Energy Conference, pp. 1-5, Oct. 2012.

[6] M. Jain, M. Daniele, and P. K. Jain, “A Bidirectional DC-DC Converter for an Energy Topology for Low Power Application," IEEE Trans. Power Electronics, vol. 15, no. 4, pp. 595-606, Jul. 2000.

[7] R. Li, A. Pottharst, N. Frohleke, and J. Bocker, "Analysis and Design of Improved Isolated FullBridge Bi-Directional DC-DC Converter," in Proceedings of Power Specialists Conference, pp. 521526, Jun. 2004.

[8] I. D. Kim, S. H. Paeng, and J. W. Ahn, "New Bidirectional ZVS PWM Sepic / Zeta DC-DC Converter," in Proceedings of Industrial Electronics, pp. 555-560, Jun. 2007.

[9] G. Feng, E. Meyer, and Y. F. Liu, "A New Digital Control Algorithm to Achieve Optimal Dynamic Performance in DC-to-DC Converters," IEEE Trans. Power Electronics, vol. 22, no. 4, pp. 1489-1498, Jul. 2007.

[10] J. S. Lee and K. B. Lee, "Variable DC-Link Voltage Algorithm with a Wide Range of Maximum Power Point Tracking for a Two-String PV System," Energies, vol. 6, no. 1, pp. 58-78, Jan. 2013.

[11] M. R. Abedi, B. M. Song, and R. Y. Kim, "Dynamic Performance Improvement of Bidirectional Battery Chargers using Predictive Current Control," in Proceedings of Power and Energy Society General Meeting, pp. 1-8, Jul. 2012.

[12] E. Figueres, G. Garcera, J. M. Benavent, M. Pascual, and J. A. Martinez, "Adaptive Two-Loop VoltageMode Control of DC-DC Switching Converters," IEEE Trans. Industrial Electronics, vol. 53, no. 1, pp. 239-253, Feb. 2006.
[13] B. Lehman and R. M. Bass, "Switching Frequency Dependent Averaged Models for PWM DC-DC Converters," IEEE Trans. Power Electronics, vol. 11, no. 1, pp. 89-98, Jan. 1996.

[14] A. Davoudi, J. Jatskevich, and T. D. Rybel, "Numerical State-Space Average-Value Modeling of PWM DC-DC Converters Operating in DCM and CCM," IEEE Trans. Power Electronics, vol. 21, no. 4, pp. 1003-1012, Jul. 2006.

[15] A. Davoudi and J. Jatskevich, "Parasitics Realization in State-Space Average-Value Modeling of PWM DC-DC Converters Using an Equal Area Method," IEEE Trans. Circuits and Systems I: Regular Papers, vol. 54, no. 9, pp. 1960-1967, Sep. 2007.

[16] S. R. Sanders, J. M. Noworolski, X. Z. Liu, and G. C. Verghese, "Generalized Averaging Method for Power Conversion Circuits," IEEE Trans. Power Electronics, vol. 6, no. 2, pp. 251-259, Apr. 1991.

[17] S. Ben-Yaakov, "Behavioral Average Modeling and Equivalent Circuit Simulation of Switched Capacitors Converters," IEEE Trans. Power Electronics, vol. 27, no. 2, pp. 632-636, Feb. 2012.

[18] A. Davoudi, J. Jatskevich, P. L. Chapman, and A. Khaligh, "Averaged-Switch Modeling of Fourth-Order PWM DC-DC Converters Considering Conduction Losses in Discontinuous Mode," IEEE Trans. Power Electronics, vol. 22, no. 6, pp. 2410-2415, Nov. 2007.

[19] R. Li, T. O’Brien, J. Lee, J. Beecroft, and K. Hwang, "Analysis of Parameter Effects on the Small-Signal Dynamics of Buck converters with Average Current Mode Control," Journal of Power Electronics, vol. 12, no. 3, pp. 399-409, May. 2012.

[20] B. Bryant and M. K. Kazimierczuk, "Modeling the Closed-Current Loop of PWM Boost DC-DC Converters Operating in CCM with Peak Current-Mode Control," IEEE Trans. Power Electronics, vol. 52, no. 11, pp. 2404-2412, Nov. 2005.

[21] R. W. Erickson and D. Maksimovic, "Fundamentals of Power Electronics," Chapman and Hall, 1997.

\section{Appendix}

$$
\begin{aligned}
& A_{1}=\left[\begin{array}{cccc}
-\frac{R_{C 1}}{L_{1}} & \frac{R_{C 1}}{L_{1}} & -\frac{1}{L_{1}} & 0 \\
\frac{R_{C 1}\left(R_{C 2}+R_{B}\right)}{\left(R_{C 2}+R_{B}\right) L_{2}} & -\frac{R_{C 1} R_{C 2}+R_{C 2} R_{B}+R_{B} R_{C 1}}{\left(R_{C 2}+R_{B}\right) L_{2}} & \frac{1}{L_{2}} & -\frac{R_{B}}{L_{2}\left(R_{C 2}+R_{B}\right)} \\
\frac{1}{C_{1}} & -\frac{1}{C_{1}} & 0 & 0 \\
0 & \frac{R_{B}}{C_{2}\left(R_{C 2}+R_{B}\right)} & 0 & -\frac{1}{C_{2}\left(R_{C 2}+R_{B}\right)}
\end{array}\right], \quad B_{1}=\left[\begin{array}{cc}
\frac{1}{2 L_{1}} & 0 \\
0 & -\frac{R_{C 2}}{\left(R_{C 2}+R_{B}\right) L_{2}} \\
0 & 0 \\
0 & \frac{1}{\left(R_{C 2}+R_{B}\right) C_{2}}
\end{array}\right] \\
& C_{1}=\left[\begin{array}{llll}
0 & \frac{R_{C 2}}{R_{B}+R_{C 2}} & 0 & \frac{1}{R_{B}+R_{C 2}}
\end{array}\right], E_{1}=\left[\begin{array}{ll}
0 & -\frac{1}{R_{B}+R_{C 2}}
\end{array}\right]
\end{aligned}
$$




$$
\begin{aligned}
& A_{2}=\left[\begin{array}{cccc}
-\frac{R_{C 1}}{L_{1}} & \frac{R_{C 1}}{L_{1}} & -\frac{1}{L_{1}} & 0 \\
\frac{R_{C 1}\left(R_{C 2}+R_{B}\right)}{\left(R_{C 2}+R_{B}\right) L_{2}} & -\frac{R_{C 1} R_{C 2}+R_{C 2} R_{B}+R_{B} R_{C 1}}{\left(R_{C 2}+R_{B}\right) L_{2}} & \frac{1}{L_{2}} & -\frac{R_{B}}{L_{2}\left(R_{C 2}+R_{B}\right)} \\
\frac{1}{C_{1}} & -\frac{1}{C_{1}} & 0 & 0 \\
0 & \frac{R_{B}}{C_{2}\left(R_{C 2}+R_{B}\right)} & 0 & -\frac{1}{C_{2}\left(R_{C 2}+R_{B}\right)}
\end{array}\right], \quad B_{2}=\left[\begin{array}{cc}
0 & 0 \\
0 & -\frac{R_{C 2}}{\left(R_{C 2}+R_{B}\right) L_{2}} \\
0 & 0 \\
0 & \frac{1}{\left(R_{C 2}+R_{B}\right) C_{2}}
\end{array}\right] \\
& C_{2}=\left[\begin{array}{llll}
0 & \frac{R_{C 2}}{R_{B}+R_{C 2}} & 0 & \frac{1}{R_{B}+R_{C 2}}
\end{array}\right], E_{2}=\left[\begin{array}{ll}
0 & -\frac{1}{R_{B}+R_{C 2}}
\end{array}\right] \\
& A=\left[\begin{array}{cccc}
-\frac{R_{C 1}}{L_{1}} & \frac{R_{C 1}}{L_{1}} & -\frac{1}{L_{1}} & 0 \\
\frac{R_{C 1}\left(R_{C 2}+R_{B}\right)}{\left(R_{C 2}+R_{B}\right) L_{2}} & -\frac{R_{C 1} R_{C 2}+R_{C 2} R_{B}+R_{B} R_{C 1}}{\left(R_{C 2}+R_{B}\right) L_{2}} & \frac{1}{L_{2}} & -\frac{R_{B}}{L_{2}\left(R_{C 2}+R_{B}\right)} \\
\frac{1}{C_{1}} & -\frac{1}{C_{1}} & 0 & 0 \\
0 & \frac{R_{B}}{C_{2}\left(R_{C 2}+R_{B}\right)} & 0 & -\frac{1}{C_{2}\left(R_{C 2}+R_{B}\right)}
\end{array}\right], B=\left[\begin{array}{cc}
\frac{D}{2 L_{1}} & 0 \\
0 & -\frac{R_{C 2}}{\left(R_{C 2}+R_{B}\right) L_{2}} \\
0 & 0 \\
0 & \frac{1}{\left(R_{C 2}+R_{B}\right) C_{2}}
\end{array}\right] \\
& C=\left[\begin{array}{llll}
0 & \frac{R_{C 2}}{R_{B}+R_{C 2}} & 0 & \frac{1}{R_{B}+R_{C 2}}
\end{array}\right], E=\left[\begin{array}{ll}
0 & -\frac{1}{R_{B}+R_{C 2}}
\end{array}\right] \\
& X=-A^{-1} B U=\left[\begin{array}{c}
\frac{D V_{D C}}{R_{B}}-\left(\frac{R_{C 2}}{R_{B}\left(R_{B}+R_{C 2}\right)}+\frac{1}{R_{B}+R_{C 2}}\right) V_{B} \\
\frac{D V_{D C}}{R_{B}}-\left(\frac{R_{C 2}}{R_{B}\left(R_{B}+R_{C 2}\right)}+\frac{1}{R_{B}+R_{C 2}}\right) V_{B} \\
D V_{D C} \\
D V_{D C}
\end{array}\right] \\
& Y=C X+E U=\left[\frac{\left(\frac{R_{C 2} L_{1}}{\left(R_{B}+R_{C 2}\right) R_{B}}+\frac{L_{1}}{R_{B}+R_{C 2}}\right) D V_{D C}}{L_{1}}-\left(\frac{\left(\frac{R_{C 2} L_{2}}{\left(R_{B}+R_{C 2}\right) R_{B}}+\frac{L_{2}}{R_{B}+R_{C 2}}\right) R_{C 2}}{\left(R_{B}+R_{C 2}\right) L_{2}}+\frac{1}{R_{B}+R_{C 2}}\right) V_{B}\right] \\
& H_{d 1}=\frac{\left.\left(L_{2} C_{1} C_{2}\left(R_{C 2}+R_{B}\right)\right) s^{3}+\left(C_{1} C_{2}\left(R_{C 1} R_{C 2}+R_{C 1} R_{B}+R_{C 2} R_{B}\right)+C_{1} L_{2}\right) s^{2}+\left(C_{2}\left(R_{C 2}+R_{B}\right)+C_{1}\left(R_{C 1}+R_{B}\right)\right) s+1\right) V_{D C}}{\left(\begin{array}{l}
\left(L_{1} L_{2} C_{1} C_{2}\left(R_{C 2}+R_{B}\right)\right) s^{4}+\left(L_{1} L_{2} C_{1}+L_{1} C_{1} C_{2}\left(R_{C 1} R_{C 2}+R_{C 2} R_{B}+R_{C 1} R_{B}\right)+L_{2} C_{1} C_{2} R_{C 1}\left(R_{C 2}+R_{B}\right)\right) s^{3}+\left(R_{C 1} C_{1} L_{2}\right. \\
\left.+L_{2} C_{2}\left(R_{C 2}+R_{B}\right)+L_{1} C_{2}\left(R_{C 2}+R_{B}\right)+L_{1} C_{1}\left(R_{C 1}+R_{B}\right)+R_{C 1} R_{C 2} R_{B} C_{1} C_{2}\right) s^{2}+\left(R_{C 2} R_{B} C_{2}+R_{C 1} R_{B} C_{1}+L_{1}+L_{2}\right) s+R_{B}
\end{array}\right)} \\
& G_{d}=\frac{\left(R_{C 1} R_{C 2} C_{1} C_{2}\left(R_{C 2}+R_{B}\right) s^{2}+\left(R_{C 2} C_{2}\left(R_{2}+R_{B}\right)+R_{C 1} C_{1}\left(R_{C 2}+R_{B}\right)\right) s+R_{C 2}+R_{B}\right) V_{D C}}{\left(R_{2}+R_{B}\right)\left(\begin{array}{l}
\left(\left(L_{1} L_{2} C_{1} C_{2}\left(R_{C 2}+R_{B}\right)\right) s^{4}+\left(L_{1} L_{2} C_{1}+R_{C 1} R_{C 2} C_{1} C_{2}\left(L_{1}+L_{2}\right)+R_{B} C_{1} C_{2}\left(R_{C 1} L_{1}+R_{C 1} L_{2}+R_{C 2} L_{1}\right)\right) \mathrm{s}^{3}\right. \\
+\left(R_{C 1} L_{2} C_{1}+R_{B} L_{2} C_{2}+R_{C 2} L_{2} C_{2}+R_{B} L_{1} C_{2}+R_{C 2} L_{1} C_{2}+R_{C 1} L_{1} C_{1}+L_{1} C_{1} R_{B}+R_{C 1} R_{C 2} R_{B} C_{1} C_{2}\right) s^{2} \\
+\left(R_{B}\left(R_{C 2} C_{2}+R_{C 1} C_{1}\right)+L_{1}+L_{2}\right) s+R_{B}
\end{array}\right)}
\end{aligned}
$$




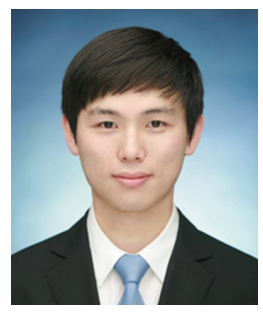

Sang-Ho Moon received the B.S. degree in Electrical and Computer Engineering from Ajou University, Suwon, Korea, in 2013. He is currently working toward the M.S degree at Ajou University, Suwon, Korea. His research interests include power conversion and multilevel inverter and reliability.

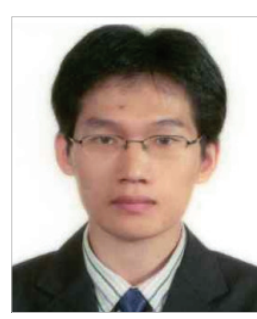

Sung-Tak Jou received the B.S. degrees in Electrical and Computer Engineering from Ajou University, Suwon, Korea, in 2005. He is currently working toward the Ph.D. degree at Ajou University, Suwon, Korea. His research interests include power conversion and electric drives.

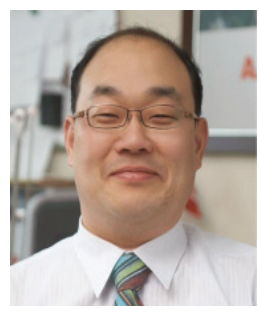

Kyo-Beum Lee received the B.S. and M.S. degrees in electrical and electronic engineering from the Ajou University, Korea, in 1997 and 1999, respectively. He received the Ph.D. degree in electrical engineering from the Korea University, Korea in 2003. From 2003 to 2006, he was with the Institute of Energy Technology, Aalborg University, Aalborg, Denmark. From 2006 to 2007, he was with the Division of Electronics and Information Engineering, Chonbuk National University, Jeonju, Korea. In 2007 he joined the School of Electrical and Computer Engineering, Ajou University, Suwon, Korea. He is an associated editor of the IEEE Transactions on Power Electronics and the Journal of Power Electronics. His research interests include electric machine drives, renewable power generations, and electric vehicles. 